\title{
Neonatal Tetanus and Gender Disparity
}

\author{
Jalal-Eddeen Abubakar Saleh ${ }^{1, ~ *, ~ J o h n ~ N e m e c e k ~}{ }^{2}$, Chester Jones ${ }^{3}$ \\ ${ }^{1}$ World Health Organization, EPI Unit, Bauchi Zonal Office, Bauchi State, Nigeria \\ ${ }^{2}$ Centre for Disease Control and Prevention, Disease Control, Atlanta, GA, U.S.A \\ ${ }^{3}$ University of Arkansas, Department Of Public Health, Kansas, U.S.A
}

Email address:

drjalals@yahoo.com (Jalal-Eddeen A. S.)

\section{To cite this article:}

Jalal-Eddeen Abubakar Saleh, John Nemecek, Chester Jones. Neonatal Tetanus and Gender Disparity. European Journal of Preventive Medicine. Vol. 3, No. 3, 2015, pp. 71-74. doi: 10.11648/j.ejpm.20150303.16

\begin{abstract}
Background: Neonatal tetanus (NNT) is a deadly vaccine preventable disease and one of the most underreported diseases in the developing countries seen in the newborn within the first 28 days of life. NNT remains one of the leading causes of deaths among neonates in the developing countries with about 130,000 neonatal deaths recorded in 2004. Despite the global success recorded in the NNT elimination strategy, Nigeria remains among the 25 remaining countries that record NNT cases. Study Design: Retrospective study Methods: This quantitative cross-sectional study involved mothers who gave birth to children with NNT within their first 28 days of life. The study used secondary data collected between January 2008 and December 2013 from northeast region of Nigeria. Results: The results revealed that $58 \%$ had male children $(\mathrm{n}=182)$ and the remaining $42 \%$ had female children $(n=130)$. The predominance of the male neonates could partly be as a result of the sociocultural preference given to the male child in Nigerian. Conclusion: There is the need for parents to promptly seek urgent medical attention for all suspected NNT cases irrespective of the gender of the child to reduce neonatal mortality rates.
\end{abstract}

Keywords: Immunization, Nigeria, Neonatal Tetanus, Neonatal Mortality, Gender Disparity

\section{Introduction}

Although efforts put in place by international agencies and government of countries towards improving the health of children across the globe has yielded positive results, arguably this is more in the developed countries than the developing countries. With an estimated 10 million annual deaths of children under the age of 5 years across the globe, it is sad to note that 4 million of these deaths occur within the first 28 days of life of these children, and in the developing countries $^{1,2,3,16,17,18}$. Thus, the burden is more on the developing countries due to the enormous challenges with high infant and neonatal death rates.

Studies show that Neonatal tetanus (NNT) is still one of the most underreported deadly vaccine preventable diseases that is commonly seen in the developing countries. In spite the increased commitment from governments of countries that have NNT, it is estimated that only $5 \%$ of cases reports to the heath services especially within the under-developed countries $^{4,5,6,16,17,18}$.

As a result of this unacceptable high neonatal mortality rates, during the World Health Assembly of 1989 and the World Summit for Children in 1990, that the WHO, UNICEF and other partner agencies developed a strategic NNT elimination framework with the initial target date in $1995^{4,5,16,17,18}$. The NNT elimination framework targets less than 1 NNT case per 1,000 live births per annum in every district of every country across the globe. The components of the framework include strengthening of routine immunization of all pregnant women with the tetanus toxoid (TT), immunization of women with 3 doses of tetanus toxoid vaccine during their childbearing age more especially those living in high-risk areas, hygienic delivery of the newborn, and improved NNT surveillance ${ }^{4,5,6,19}$. As a result of failure of several countries to meet with the deadline, the target date for the global NNT elimination was revised to $2015^{5,6,16,17,18}$.

In spite the fact that this strategic plan has yielded remarkable improvement in NNT across the globe evidenced by a $93 \%$ reduction in cases, statistics shows that as at December 2013 there are still 25 countries that fail short of meeting with the NNT elimination goals. Notably, Nigeria, with all its vast human and capital resources is among the 25 remaining countries with unacceptably high prevalence of $\mathrm{NNT}^{5,16,17,18}$. 
The study was conducted in the northeast region of Nigeria; this sub-region comprises of six provinces: Adamawa, Bauchi, Borno, Gombe, Taraba, and Yobe. As shown in the Demographic and Health Survey of 2008, the northeast region has an interesting health statistics: total fertility rate of 7.2 (national 5.7), women age 15-19 who are mothers $39 \%$ (national 23\%), women who gave birth in the last 5 years and received antenatal care from a skilled provider $43 \%$ (national $58 \%$ ), Births assisted by a skilled provider $16 \%$ (national $39 \%$ ), Births delivered in a health facility $13 \%$ (national $35 \%$ ), Children $12-23$ months fully immunized $8 \%$ (national $23 \%$ ), Children 12-23 months with no immunizations 33 (national 29\%), Literate women age 15-49/men age 15-49, stands at $23 / 54$ (national $54 / 77 \%$ ), and those with no education women age $15-49 / \mathrm{men}$ age $15-49$, stands at $68 / 45$ (national 36/19\%) ${ }^{8}$.

\section{Methodology}

The study is a cross-sectional quantitative study and retrospective in nature. The secondary data used is the NNT dataset that was collected from $2008-2013$. The sample size of the participants was 312 mothers who gave birth to NNT babies. As compared with the southern region of Nigeria, the northeast region is less densely populated. With Islam and Christianity as the two dominant religions, the rural dwellers in the region are mostly farmers and often with large-scale production of crops and livestock. In comparison with other regions in Nigeria, the northeast region has poorer economic indices and worse health outcomes ${ }^{7,8}$.

The selection criteria for is that eligible participants are mothers of child bearing age from the six provinces who gave birth to newborn children that died within the first 28 days of life as a result of symptoms inline with the standard NNT case definition or as diagnosed by a clinician as NNT.

This research work obtained ethical approval for the use of the NNT dataset from the zonal office of the National Primary Health Care Development Agency. The NNT data was collected from eligible participants in the northeast region using a standard tool. Informed of consent of the participants was obtained from the local authorities and the husbands of these women prior administering the questionnaire. The participants were well informed in the local language that they understood on the purpose of administering the questionnaire. The information obtained was securely kept in the official database, and restricting data access except to authorize persons.

The instrument used for collecting data from the respondents has on its various columns the following: the first column for capturing demographic information of the NNT child, as well as that of the parents. Other columns are tailored to obtain information on the mother's vaccination history, birth of an infant, initial clinical history, treatment, action taken in the form of response, and final classification of the case. To ensure that the outcome is valid and generalizable, quality of the items was sought with content validity. The content of the instrument clearly measures what it was expected to measure; thus validity and reliability of the measurement instrument was well tested ${ }^{9,10}$.

\section{Results}

The authors used Statistical Package for the Social Sciences (SPSS) version 22 to code and tabulate the scores collected from the survey. The summary of values, where applicable, includes the mean, central tendency, variance, and standard deviation. Both inferential and descriptive statistics were used to draw conclusions from the sample.

As shown in Table 1, the data collected from a sample of 312 mothers from the northeast region of Nigeria revealed that $58 \%(182 / 312)$ of the participants had male children $(n$ $=182)$ and the remaining $42 \%(130 / 312)$ had female children $(n=130)$. Furthermore, $8 \%(25 / 312)$ were from Adamawa province $(n=25), 20 \%(62 / 312)$ were from Bauchi province $(n=62), 28 \%(86 / 312)$ were from Borno $(n=86), 17 \%$ $(53 / 312)$ were from Gombe province $(n=53), 18 \%(55 / 312)$ were from Taraba province $(n=55)$, and the remaining $10 \%$ $(31 / 312)$ were from Yobe province $(n=31)$. Additionally, Table 2 shows that highest number of neonates who had NNT [26\% (80/306)] was in 2010, whereas fewer neonates had NNT [9\% (27/306)] in 2013.

Table 1. Cross Tabulation of the Sex of Participants' Baby and Province.

\begin{tabular}{llll}
\hline \multirow{2}{*}{ Province } & \multicolumn{2}{c}{ Sex of Baby } & \multirow{2}{*}{ Total } \\
\cline { 2 - 3 } & Male & Female & 25 \\
\hline Adamawa & 6 & 19 & 62 \\
Bauchi & 43 & 19 & 86 \\
Borno & 48 & 38 & 53 \\
Gombe & 34 & 19 & 55 \\
Taraba & 26 & 29 & 31 \\
Yobe & 25 & 6 & 312 \\
Total & 182 & 130 & \\
\hline
\end{tabular}

Table 2. Cross Tabulation of the Babies' Birth Year and Province.

\begin{tabular}{lllllllll}
\hline \multirow{2}{*}{ Province } & \multicolumn{2}{l}{ Birth Year } & & & & \multirow{2}{*}{ Total } \\
\cline { 2 - 7 } & $\mathbf{2 0 0 8}$ & $\mathbf{2 0 0 9}$ & $\mathbf{2 0 1 0}$ & $\mathbf{2 0 1 1}$ & $\mathbf{2 0 1 2}$ & $\mathbf{2 0 1 3}$ & \\
\hline Adamawa & 1 & 2 & 5 & 7 & 7 & 3 & 25 \\
Bauchi & 1 & 16 & 21 & 14 & 8 & 1 & 61 \\
Borno & 17 & 29 & 22 & 6 & 4 & 8 & 86 \\
Gombe & 3 & 6 & 10 & 11 & 13 & 9 & 52 \\
Taraba & 3 & 15 & 16 & 5 & 9 & 6 & 54 \\
Yobe & 13 & 7 & 6 & 2 & 0 & 0 & 28 \\
Total & 38 & 75 & 80 & 45 & 41 & 27 & 306 \\
\hline
\end{tabular}

From the sample of 312 participants, two said they had a child without NNT $(n=2)$, and five did not respond to NNT status $\left(n_{\text {missing }}=5\right)$. The two NNT babies were both males with different backgrounds. That is, case \#157 was born in 2008 in the Borno province and the mother did not receive antenatal care, nor was she attended by a TBA; whereas, case \#260 was born in 2009 in the Taraba province, had received antenatal care, and had the umbilical cord treated. 
Demographic statistics of the two participants with non-NNT displayed in Table 3. babies and those that did not respond to NNT status were

Table 3. Demographic Breakdown of Participants who gave Birth to NNT Babies and those that did not Respond to NNT Status.

\begin{tabular}{lllllll}
\hline Case \# & Gender & Province & Birth Year & Received Care & Attended by TBA & Cord Treated \\
\hline NNT Baby & & & & & & \\
$\# 157$ & Male & Borno & 2008 & No & No & n/a \\
$\# 260$ & Male & Taraba & 2009 & Yes & & Yes \\
Missing & & & & No & No \\
$\# 112$ & Male & Borno & 2009 & No & No & No \\
$\# 118$ & Female & Borno & 2009 & No & No & No \\
$\# 119$ & Female & Borno & 2009 & No & Yes & nes \\
$\# 178$ & Male & Gombe & 2010 & Yes & & Yes \\
$\# 201$ & Male & Gombe & 2010 & & &
\end{tabular}

Note. $\mathrm{n} / \mathrm{a}=$ no response provided

\section{Discussion}

The authors used Statistical Package for the Social Sciences (SPSS) 22 to analyze the data. Descriptive statistics and exploratory analysis for the differences in frequency between the variables was conducted.

The result of this study shows that there were more male neonates with neonatal tetanus as compared with female neonates. The predominance of the male neonates among reported NNT cases is in agreement with other previous studies $^{11-15}$. While outright reason for the dominance of male neonates with NNT in this study could not be ascertained, the disparity between the reported cases could partly be as a result of the socio-cultural preference given to the male child in the Nigerian community, which makes parents seek medical attention for the male child promptly as against the female child ${ }^{15}$.

In a related study in India, it was observed that the excess female neonatal mortality recorded is as a result of sexselective prenatal care in maternal tetanus vaccination. The study added that mothers attend ANCs to get vaccinated with the TT more often when the baby in-utero is a boy as compared to a girl $^{20}$.

Although significant achievement has been made in the current global fight against maternal and neonatal tetanus (MNT), much needs to be done in the developing countries such as Nigeria. Considering the deadly nature of NNT even in the best of centres, there is need for policy makers and stakeholders to increase awareness of the parents about the disease and educate them on the need to promptly seek urgent medical attention for all suspected NNT irrespective of the gender of the child. This would help meet up with the MDG goals to improve the health indicators by reducing mortality rates in the under fives.

\section{Acknowledgements}

The authors would like to acknowledge the NPHCDA for allowing the use of the NNT dataset for the sole purpose of this study.

\section{References}

[1] WHO (2004). "The Global Burden of Disease 2004 Update" Retrieved from http://www.who.int/healthinfo/global_burden_disease/2004_re port_update/en/index.html

[2] Kippengerg, R., Lawn, J., Darmstadt, G., Begkyoyian, G., ....Paul, V. (2005). Neonatal survival 3: Systematic scaling up of neonatal care in countries. The Lancet, 365,1087-98. Retrieved

http://www.ncbi.nlm.nih.gov/pubmed/15781104

[3] The MDG Report (2012). We can end poverty 2015. UN Publication, New York. Retrieved from http://www.endpoverty2015.org/en/category/millenniumdevelopment-goals/

[4] Roper, M.H., Vandelaer, J.H., \& Gasse, F.L. (2007). Maternal and neonatal tetanus. Lancet;370:1947-59.

[5] UNICEF, WHO, UNFPA (2000). Maternal and neonatal tetanus elimination by 2005. Strategies for achieving and maintaining elimination. Retrieved from http://www.unicef.org/health/files/MNTE\%5Fstrategy\%5Fpap er.pdf

[6] WHO (2014). Maternal and Neonatal Tetanus (MNT) elimination: The initiative and challenges. Retrieved from http://www.who.int/immunization/diseases/MNTE_initiative/e $\mathrm{n} /$

[7] Central Intelligence Agency (2014). The World Fact book: Country Comparison. Retrieved from https://www.cia.gov/library/publications/the-worldfactbook/geos/ni.html

[8] Nigeria Demographic and Health Survey (2008): North East. UNICEF 2009 Publication. Retrieved from http://www.unicef.org/nigeria/ng_publications_North_East_zo nal_fact_sheet_(English).pdf

[9] Frankfort-Nachmias, C., \& Nachmias, D. (2008). Research methods in the social sciences (7th ed.). New York: Worth.

[10] Szklo, M. \& Nieto, F.J. (2014). Epidemiology: Beyond the basics (3rd ed.). Sudbury, MA: Jones and Bartlett 
[11] Ibadin, M. O., \& Omoigberale, A. I. (1996). Neonatal tetanus in Benin City, Nigeria: A decade after commencement of expanded programme on immunization (EPI). Niger Med Journal, 5, 55-7.

[12] Oruamabo, R. S., \& Mbuagbaw, L. T. (1986). Neonatal tetanus in Port Harcourt. Niger J Paediatrics, 13, 115-20. Retrieved

from http://www.njpaediatrics.com/1986/v13n4/2Neonatal\%20Teta nus\%20in\%20Port-Harcourt.pdf

[13] Osinusi, K., Dawodu, A. H., Sodeinde, O., \& Adeyokunnu, A. A. (1986). Neonatal tetanus in Ibadan. Niger J Paediatrics, 13, $121-5$. Retrieved from http://www.njpaediatrics.com/1986/v13n4/3Neonatal\%20Teta nus\%20in\%20Ibadan.pdf

[14] Okoromah, C. N., Lesi, F. E. A., Egri-Okwaji, \& M. T. C., Iroha, E. O. (2003). Clinical and management factors related to outcome in Neonatal tetanus. Niger Postgrad Med Journal, 10, 92- 5. $\quad$ Retrieved from http://www.ncbi.nlm.nih.gov/pubmed/14567043

[15] Alhaji, M. A., Bello, M. A., Elechi, H. A., Akuhwa, R. T., Bukar, F. L., \& Ibrahim, H. A. (2013). A review of neonatal tetanus in University of Maiduguri Teaching Hospital, northeastern Nigeria. Niger Med J, 54(6): 398-401. doi: $10.4103 / 0300-1652.126294$
[16] Abdulkarim, A.A., Ibrahim, R.M., Fawi, A.O., Adebayo, O.A., \& Johnson, B.R. (2011). Vaccines and immunization: The past, present and future in Nigeria. Niger J Paediatrics, 38, 186-94. doi.org/10.4314/njp.v38i4.72382

[17] Akani, N. A., Nte, A. R., \& Oruamabo, R. S. (2004). Neonatal tetanus in Nigeria: One social scourge too many! Nig J of Paediatrics, 3, 1-9. Retrieved from http://www.ajol.info/index.php/njp/article/viewFile/12080/151 98

[18] Blencowe, H., Lawn, J., Vandelaer, J., Roper, M., \& Cousens, S. (2010). Tetanus toxoid immunization to reduce mortality from neonatal tetanus. Int J of Epidemiology, 39, i102-i109. doi:10.1093/ije/dyq027

[19] Saleh, J-E. A., Nemecek, J., \& Jones, C. (2015). Antenatal care services and neonatal tetanus: An outlook at the northeastern Nigeria. Pediatric Infectious Disease. Retrieved from http://dx.doi.org/10.1016/j.pid.2015.03.001

[20] Bharadwaj, P. \& Lakdawala, L.K. (2013). Discrimination Begins in the Womb: Evidence of Sex-Selective Prenatal Investments. J. Human Resources, 48:71-113. Retrieved from http://jhr.uwpress.org/content/48/1/71.short. 